\title{
Publisher Correction: Guided self-organization and cortical plate formation in human brain organoids
}

\author{
Madeline A Lancaster, Nina S Corsini, Simone Wolfinger, E Hilary Gustafson, Alex W Phillips, Thomas R Burkard, Tomoki Otani, \\ Frederick J Livesey \& Juergen A Knoblich \\ Nat. Biotechnol. 35, 659-666 (2017); published online 31 May 2017; corrected after print 14 August 2018
}

In the HTML and PDF versions of this article initially published, $\mu$ 's appeared as m's throughout the scale bar lengths in the figure legends, as well as in the Methods section in the phrases "added to give a final volume of $150 \mu$ per well," "an average hPSC cell size of $15 \mu \mathrm{m}$ " and "sectioned on a vibratome to collect $300-\mu \mathrm{m}$ sections." In the HTML version, $\mu$ 's appeared as m's in all instances throughout the Methods section except " $35 \mu \mathrm{g} / \mathrm{ml}$ of pure laminin" and " $35 \mu \mathrm{l}$ laminin/entactin $+25 \mu \mathrm{l}$ collagen." The errors have been corrected in the HTML and PDF versions of the article.

\section{Author Correction: Precision medicine in the clouds}

\section{Henrik Vogt, Sara Green \& John Brodersen}

Nat. Biotechnol. 36, 678-680 (2018); published online 6 August 2018; corrected after print 4 September 2018

In the version of this article initially published, author John Brodersen's name was misspelled Broderson and a second affiliation for him was missing: Primary Health Care Research Unit, Region Zealand, Denmark. The error has been corrected in the HTML and PDF versions of the article. 